\title{
INTERNATIONAL COMMISSION OF ZOOLOGICAL NOMENCLATURE ANNOUNCEMENT
}

Required 6 months' notice is given of the possible use of plenary powers by the International Commission on Zoological Nomenclature in connexion with the following names listed by case number: (see Bull. Zool. Nom. 32 part 4, 30 January 1976).

260. Dermacentor andersoni Stiles, 1908 (Acarina: IXODIDAE): proposed conservation.

1772. Ophiura Lamark, 1801 and Ophioderma Müller \& Troschel, 1840: revised proposals for stabilization.

2097. Ophiolensis Müller \& Troschel, 1840: proposed designation of type-species.

2112. Circinae in Aves and Mollusca: proposals to end the homonymy.

2113. Pterois zebra Quoy \& Gaimard, 1825 (Pisces: SCORPAENIDAE): proposed suppression.

2116. Halecium Oken, 1815 (Coelenterata: Hydroida): Proposed validation: Thoa Lamouroux, 1816, proposed suppression.

2119. Lecanium acuminatum Signoret, 1873 (Hemiptera: CoccidaE) proposed designation of neotype.

2120. Cystioceras Börner, 1912 (Insecta: Collembola): proposed suppression.

Comments should be sent in duplicate, citing case number, to the Secretary, International Commission on Zoological Nomenclature, c/o British Museum (Natural History), Cromwell Road, London, $\mathrm{SW}_{7}$ BD, England, as soon as possible. Those received early enough will be published in the Bulletin of Zoological Nomenclature.

R. V. MELVILLE

Secretary to the International Commission on Zoological Nomenclature. 